\title{
Analysis of Water Flow Pressure on Bridge Piers considering the Impact Effect
}

\author{
Yin-hui Wang, ${ }^{1}$ Yi-song Zou, ${ }^{2}$ Lue-qin $\mathrm{Xu}^{2}$ and Zheng Luo ${ }^{1}$ \\ ${ }^{1}$ Ningbo Institute of Technology, Zhejiang University, Ningbo, Zhejiang 315100, China \\ ${ }^{2}$ School of Civil Engineering and Architecture, Chongqing Jiaotong University, Chongqing 400074, China \\ Correspondence should be addressed to Yi-song Zou; zys200595@aliyun.com
}

Received 15 September 2014; Accepted 27 January 2015

Academic Editor: Chenfeng Li

Copyright (c) 2015 Yin-hui Wang et al. This is an open access article distributed under the Creative Commons Attribution License, which permits unrestricted use, distribution, and reproduction in any medium, provided the original work is properly cited.

\begin{abstract}
In order to investigate the effects of water current impact and fluid-structure interaction on the bridge piers, the mechanism of water flow impact on the bridge pier is firstly studied. Then a finite element model of a bridge pier is established including the effects of water flow impact as well as the water circumferential motion around the pier. Comparative study is conducted between the results of water impact effect, fluid-structure coupling effect, theoretical analysis, and also the results derived using the formulas specified in the design codes home and abroad. The results show that the water flow force calculated using the formulas provided by the codes should be multiplied by an impact amplifier to account for the effect of flood impact on the bridge pier. When the flood flows around the pier, the fluid-structure coupling effect on the bridge pier can be neglected. The method specified in the China guidelines of General Code for Design of Highway Bridges and Culverts tends to provide a larger result of the water flow force.
\end{abstract}

\section{Introduction}

Over the last 30 years, a lot of bridges were damaged by the flood, such as the Schoharie Creek Bridge [1] in New York damaged in 1987, the Hatchie Bridge [2] in Tennessee damaged in April 1989, and the Hintze Ribeiro Bridge [3] in Portugal damaged in 2001. Damage of these bridges can all be attributed to or partially attributed to destabilization of the bridge pier. Generally, a great majority of bridges are built across rivers, and routinely the water flow force on the pier is calculated using the methods specified in the design codes. When the rainstorm comes, the pier is not submerged in water in the downstream side at the moment of the flood impacting the pier, and the water flow force on the pier at the very moment cannot be determined using the methods provided by the design codes, since the methods only apply to the case of flood flowing around the pier. In most cases, the pier is impacted by the flood in a small range of heights; hence the impact effect and the fluid-structure coupling effect of the flood have a lower influence on the static analysis of the bridge pier. But when the bridge pier is transiently impacted by the flood over a large range of heights, for example, a river bridge encountered by a catastrophic flood, or an inshore bridge struck by a large tidal current, or a bridge pier in the deep water attacked by big waves; it is necessary to investigate whether the impact effect and the fluid-structure coupling effect can be neglected. In the design code of bridges, it is stipulated that the automobile shock effects need to be considered while computing the vehicle loading, whereas the impact effects of water are not such elaborately specified. The impact effects of fluids are more widely studied in the field of tubes and pumps [4-11], where they are called line shock or water hammer. However, in the field of bridge engineering, few research efforts are made to examine the potential destructive effect of the water flow pressure on the pier $[12,13]$.

Many references can be found in literature with regard to the investigation of wave or wave current forces on cylinders. For the calculation of wave current forces on single pile, the commonly used formula is the Morison equation, in which the hydrodynamic coefficients $C_{D}$ and $C_{M}$ can be determined by the $K C$ parameter calculated under the wave and current conditions. Li [14] discussed the normalization of the hydrodynamic coefficients in the Morison equation. Sundar et al. [15] gave a detailed review on the hydrodynamics of slender 


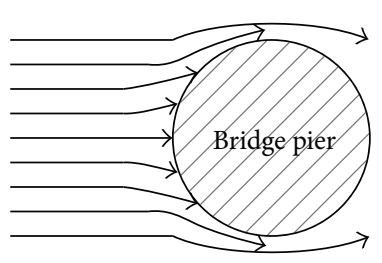

(a)

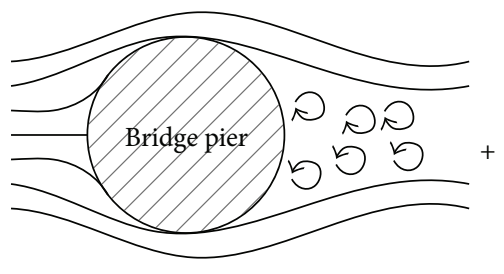

(b)

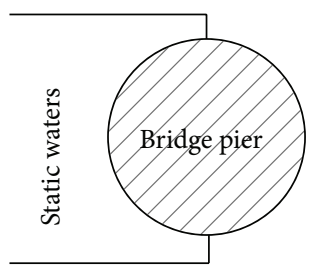

(c)

FIGURE 1: Schematic view of water flow force on bridge pier considering the impact of the flood against the pier.

piles and the variations of the hydrodynamic coefficients with the $K C$ parameter. But for the wave current forces on pile groups, only simple combinations as tandem and parallel arrays of two or three piles were investigated. The Chinese Code of Hydrology for the Design of Sea Harbor [16] gave the specification of group effective factor for bi- and tripile groups. On the basis of foundation designed for the East Sea Bridge, Y. C. Li and G. W. Li [12] experimentally investigated the wave current forces on oblique piles considering the effect of the super structures, and Lan et al. [17] gave the experimental results for the effect of hydrodynamic forces on pile array and slab in wave current combinations. Except for the wave current forces on the base foundation, the scour around the structures is another problem for engineering design $[3,18]$.

Based on qualitative analysis of the mechanism of water flow transient impact on the bridge pier, finite element models are established, and the impact effect and the fluidstructure coupling effect of the flood on static analysis of the bridge pier are investigated. The results including the fluidstructure coupling effect are compared with those obtained from calculation using formulas specified in design codes home and abroad. The paper is devoted to providing a reliable reference for further research and practical engineering.

\section{Action Mechanism of the Water Current Loads on the Bridge Piers}

When the flood impacts the bridge pier, the other investigated topic is that the calculation of dynamic response and flow current pressure taking fluid-structure interaction into account. Miquel and Bouanani [19] proposed a practical formulation to investigate the dynamic response of structures laterally vibrating in contact with water on one or both sides and developed simplified procedures for practical assessment of the vibration periods, hydrodynamic loads, and seismic response of structure-water systems including higher mode effects. However, relatively few systematic investigations have been carried out on the pier with water flow pressure considering impact effect, especially taking fluid-structure interaction into account.

When the flood impacts the bridge pier, the impact process on the pier caused by the flow can be disintegrated into two parts: the moment impact that flood impacts the bridge pier and the motion that water flows around the pier after the moment impact.
The flowing velocity of the flood will be rapidly influenced when flow impacts pier. Due to lack of constraint, most of water will flow forward along the walls of two sides of pier, but part of water will stop flowing or even flow backward because of being obstructed by pier, as shown in Figure 1(a). Therefore, at the moment of which flow impacts pier, the moment impact effect, as "water hammer effect," which is far larger than the effect of static fluid pressure, will be generated on the pier.

After the flood impacts the bridge pier, water always flows around the pier, as shown in Figure 1(b). The positive side of pier bears higher pressure, and the back side of pier bears lower pressure. The dynamic water pressure is induced by these pressure differences around the pier. The structure generates vibration and deformations because of this dynamic water pressure, and the fluid field will be influenced by the motional pier; the distribution and magnitude of dynamic water pressure are changed accordingly.

If the fluid reflection waves induced by the flood are neglected, the flow current load on the piers is equivalent to the summation of the impact effect, the dynamic water pressure, and the static water pressure, where the dynamic water pressure is generated by the water flowing around the pier, as shown in Figure 1.

The flowing velocity of the flood is always quite large, ranging between $4 \mathrm{~m} / \mathrm{s}$ and $15 \mathrm{~m} / \mathrm{s}$. Traditionally, a current with its velocity ranging above $15 \mathrm{~m} / \mathrm{s} \sim 20 \mathrm{~m} / \mathrm{s}$ can be deemed to be a high-velocity flow, and, therefore, the problem of the flood impacting the bridge pier still belongs to the research field of low-velocity flow, where the classical hydromechanics theory can be applied. In this paper, in order to investigate the impact effect of the flood on bridge pier, it is assumed that all the bridge piers are not submerged in the water before the flood comes.

\section{Construction of FEM Models}

3.1. Numerical Calculation Method considering Fluid-Structure Coupling Effect. The problem that fluid impacts structure is typical two-way fluid-structure interaction (FSI) problem. The structure will generate vibration and deformations because of dynamic loads induced by fluid flowing; meanwhile the fluid field will be influenced by the motional pier; the distribution and magnitude of fluid loads will be changed accordingly. 


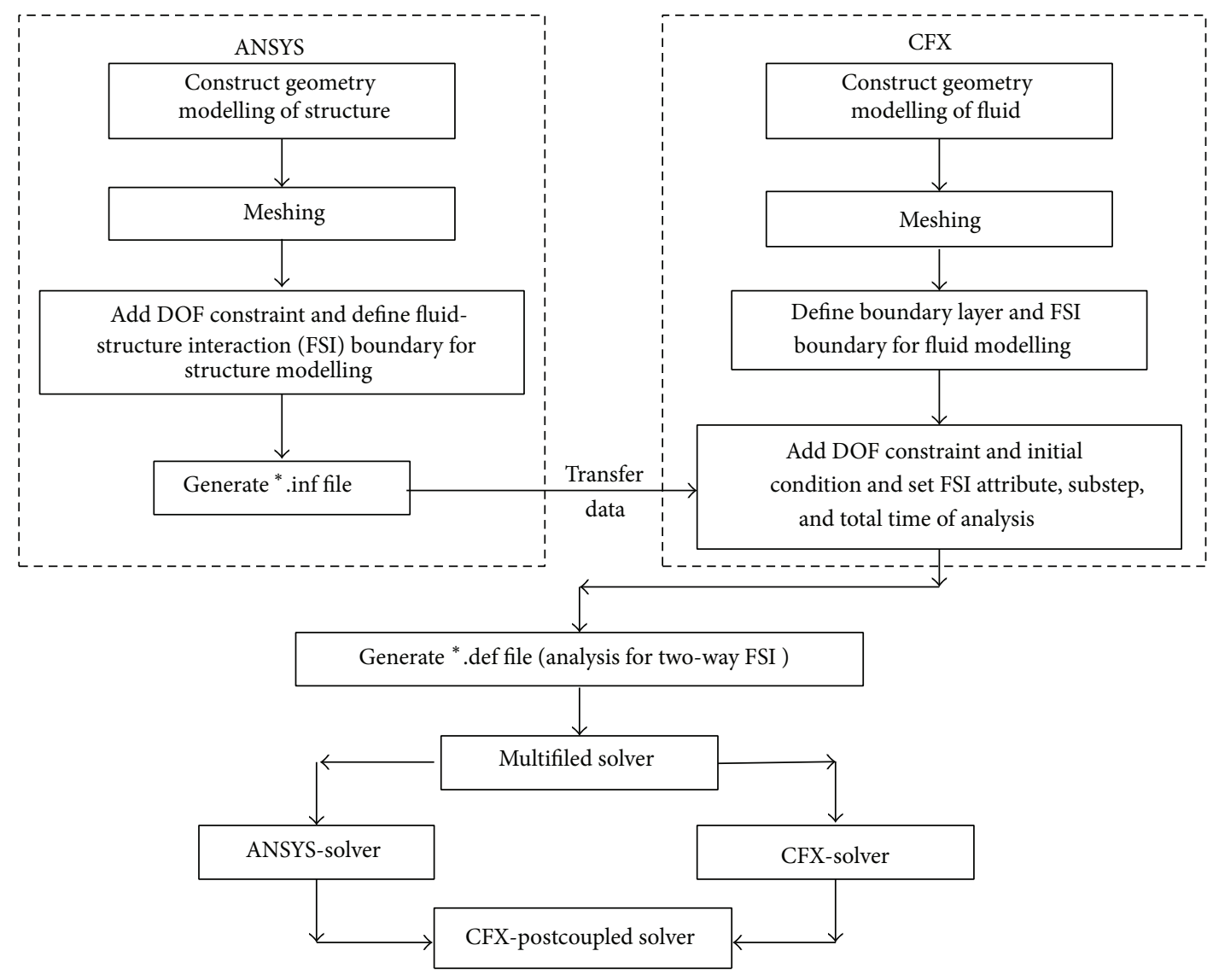

FIgUre 2: The flow of the CFX-ANSYS two-way FSI analysis.

CFX is computational fluid dynamics software integrated with ANSYS. A fluid-structure coupled model is built up by finite element method. And the vibration response of structure is calculated by the ANSYS combined with CFX. The flow of the CFX-ANSYS two-way FSI analysis is shown in Figure 2.

3.2. Construction of FEM Models. In order to study the behavior of the bridge pier under the dynamic fluid-pier coupling effect, comparative models are established. The bridge pier is a cantilever column with the bottom fixed and the top free. The circular pier is $H=10.0 \mathrm{~m}$ in height, with a sectional radius of $R=1.0 \mathrm{~m}$. With regard to the material properties of the bridge pier, the mass density is $\rho_{1}=2400 \mathrm{~kg} / \mathrm{m}^{3}$, the elasticity modulus is $E=3.0 \times 10^{10} \mathrm{~Pa}$, and the Poisson ratio is $\mu=0.2$. As concerns the properties of the water body flowing around the pier, the mass density is $\rho_{2}=1000 \mathrm{~kg} / \mathrm{m}^{3}$ and the sonic velocity under the water is $\nu=1460 \mathrm{~m} / \mathrm{s}$. The geometric dimensions of the dynamic water body around the bridge pier are $80 \mathrm{~m}$ long and $20 \mathrm{~m}$ wide, with a varying height ranging from $1 / 4 H$ to $8 / 8 H$, where the varying increment is defined as $1 / 4 H$. Changing the water flow velocity, the impact effect under different velocities can be investigated. In the paper, the water flow velocity is set as $v=1.0 \sim 15.0 \mathrm{~m} / \mathrm{s}$, with a varying increment of $1.0 \mathrm{~m} / \mathrm{s}$. Initial flow velocity is defined at the inlet of the flow field, and the relative static pressure is set as zero at the outlet and opening of the flow field. The variables transferred by fluid-structure coupling effect and the movement of mesh grids are recorded at the interface between the bridge pier and the flow field. Both side surfaces of the flow field are defined as symmetric boundary conditions, while the wall of the flow field is defined as sliding wall, as shown in Figure 3.

The models of pier and external water are constructed by ANSYS software, as shown in Figure 4 . Solid45 structure finite elements (3D solid45 element with 8 nodes and 24 degrees of freedom) are used to simulate pier. Fluid30 fluid finite elements (3D element with 8 nodes) are used to simulate external water. For fluid elements that are in contact with the pier element, be sure to use $\operatorname{KEYOPT}(2)=0$, the default setting that allows for fluid-structure interaction, which results in unsymmetric element matrices with UX, UY, UZ, and PRES as the degrees of freedom. For all other fluid elements, set $\operatorname{KEYOPT}(2)=1$, which results in symmetric element matrices with the PRES degree of freedom. Fluid130 elements, which are infinite fluid elements, are used to simulate the fluid meshes at outer most layer.

\section{Analysis of Water Flow Pressure on the Bridge Pier}

4.1. The Moment Impact Effect of the Coupled Fluid-Structure System. The maximum displacement at the top of the bridge 

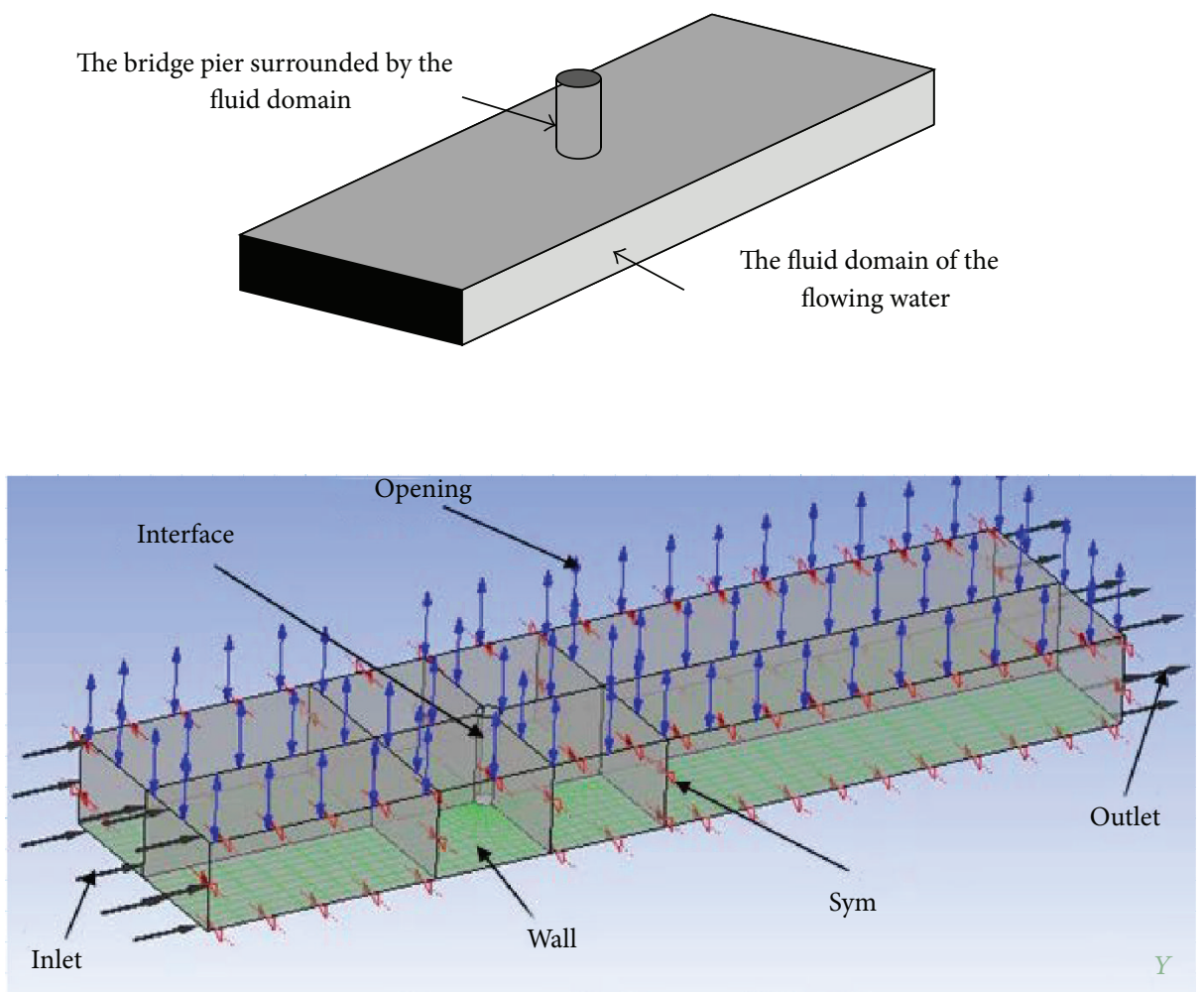

FIGURE 3: FEM model of the bridge pier and the flow field as well as the definition of boundary conditions for the fluid body.
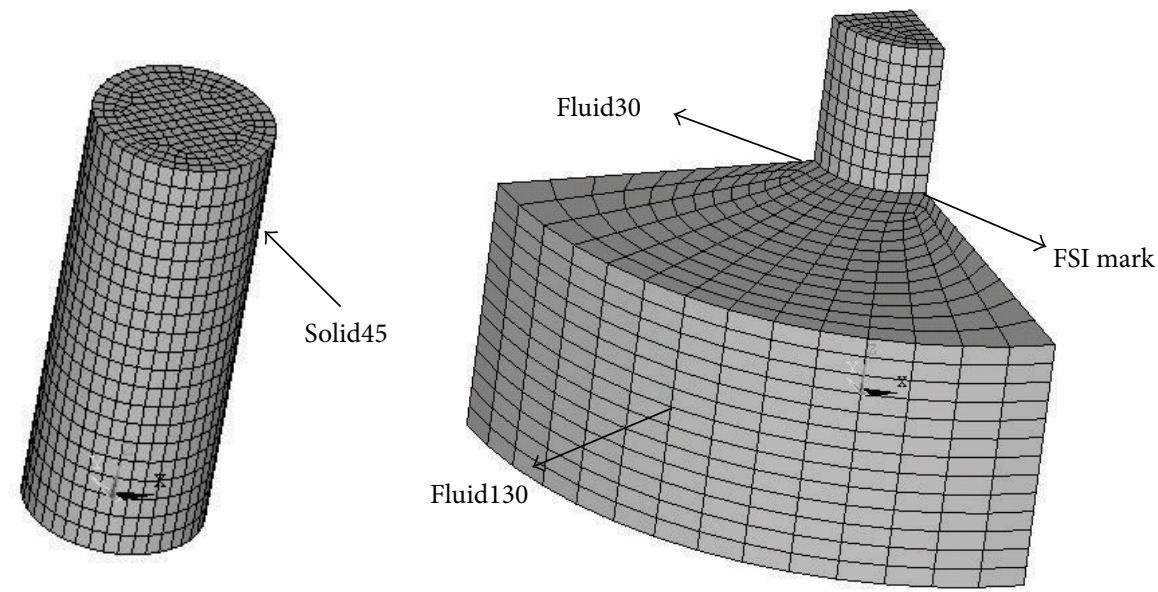

FIgURE 4: The calculation model of the column bridge pier and external water.

pier, and the maximum stress at the bottom section of the bridge pier are investigated. Figure 5 shows the variation of the impact amplification coefficient (IAC) with respect to the flow velocity, where the IAC is defined as the ratio of the numerical response of the bridge pier under the water flowing pressure considering the fluid-structure coupling effect and the impact effect when the flood impacts the bridge pier in a transient state, to the theoretical response of the bridge pier under the water flowing pressure excluding the impact effect.
It can be found in Figure 5 that (1) taking the displacement and the stress as investigation quantities the IAC tends to increase to some extent and then decrease, when the flood flow velocity increases gradually; (2) the maximum IAC decreases when the ratio of the pier depth submerged in the flood to the total height of the pier (S-ratio) increases; (3) when the S-ratio increases, the flood flow velocity corresponding to the maximum IAC is also increasing; (4) the variation curves of the IAC with respect to the flood flow 

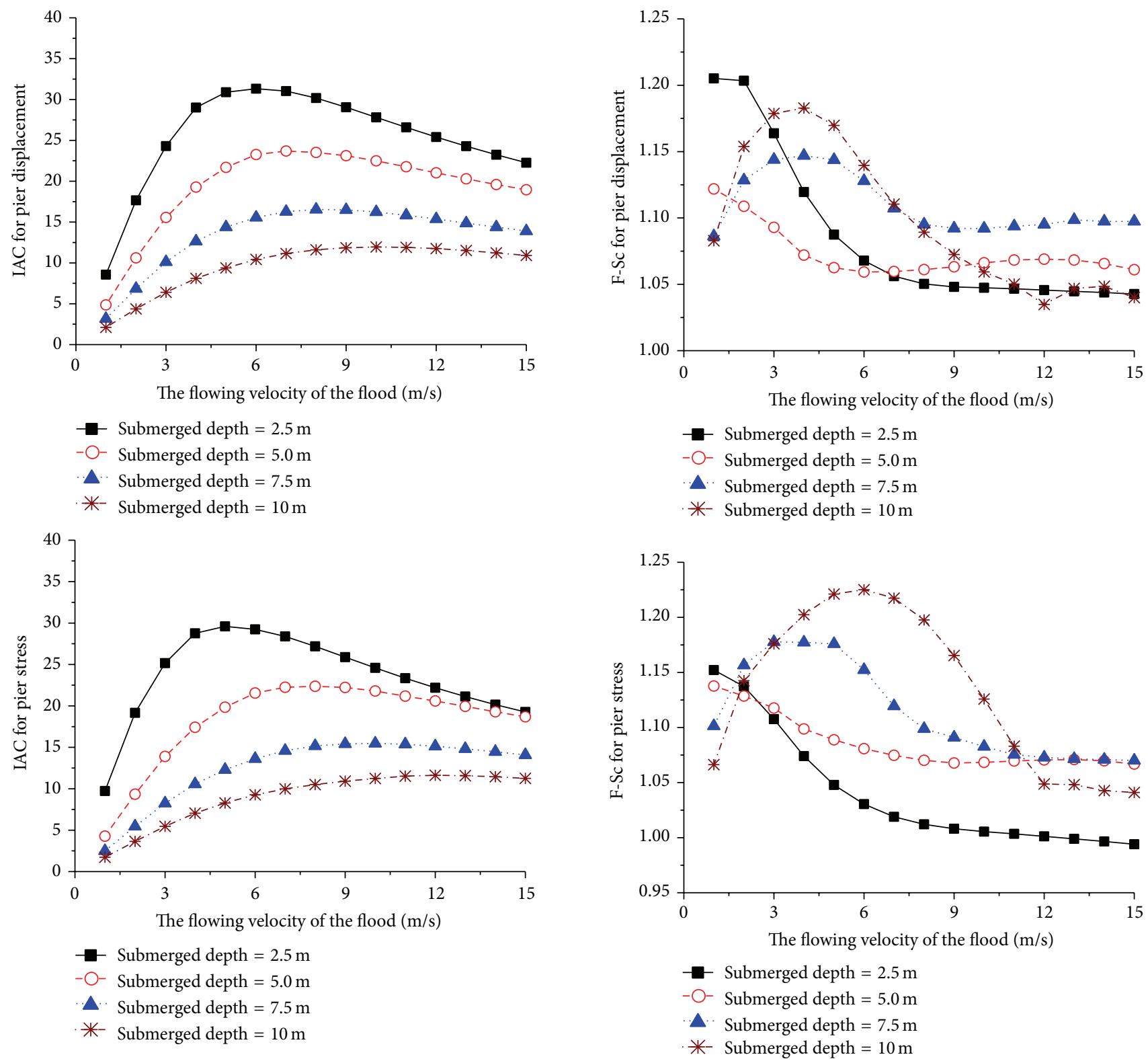

Figure 5: Variation curves of the IAC with respect to the flood flowing velocity.

velocity tend to flatten, when the S-ratio increases. It can be seen that the IAC has a close relation with the flood flowing velocity and the S-ratio.

4.2. Influence of Fluid-Structure on the Dynamic Water Pressure after the Moment Impact. To further investigate the influence of fluid-structure coupling effect on the water flow pressure applied to the bridge pier when the flood impacts the pier in a stable state, the maximum displacement at the top of the bridge pier and the maximum stress at the bottom section of the bridge pier are considered as investigation quantities. Figure 6 shows the variation of the fluid-structure coupling effect coefficient $(\mathrm{F}-\mathrm{Sc}$ ) with respect to the flow velocity, where the F-Sc is defined as the ratio of the numerical
FIGURE 6: Variation curves of the F-Sc with respect to the flood flow velocity.

response of the bridge pier under the water flowing pressure considering the fluid-structure coupling effect when the flood impacts the bridge pier in a stable state, to the response of the bridge pier under the water flowing pressure excluding the fluid-structure coupling effect.

The following can be found from Figure 6. (1) When the Sratio is not larger than $1 / 2$, the F-Sc decreases as the flood flow velocity increases; when the flood flowing velocity reaches $6.0 \mathrm{~m} / \mathrm{s}$, the F-Sc trends towards a stable constant with a value of about 1.1. (2) When the S-ratio is not smaller than $1 / 2$ and the flood flowing velocity is not larger than $4.0 \sim 6.0 \mathrm{~m} / \mathrm{s}$, the F-Sc increases to a maximum value as the flood flowing velocity increases. Under this case, when the S-ratio equals $h / H=0.75$, the $\mathrm{F}-\mathrm{Sc}$ reaches a maximum value of 1.19 


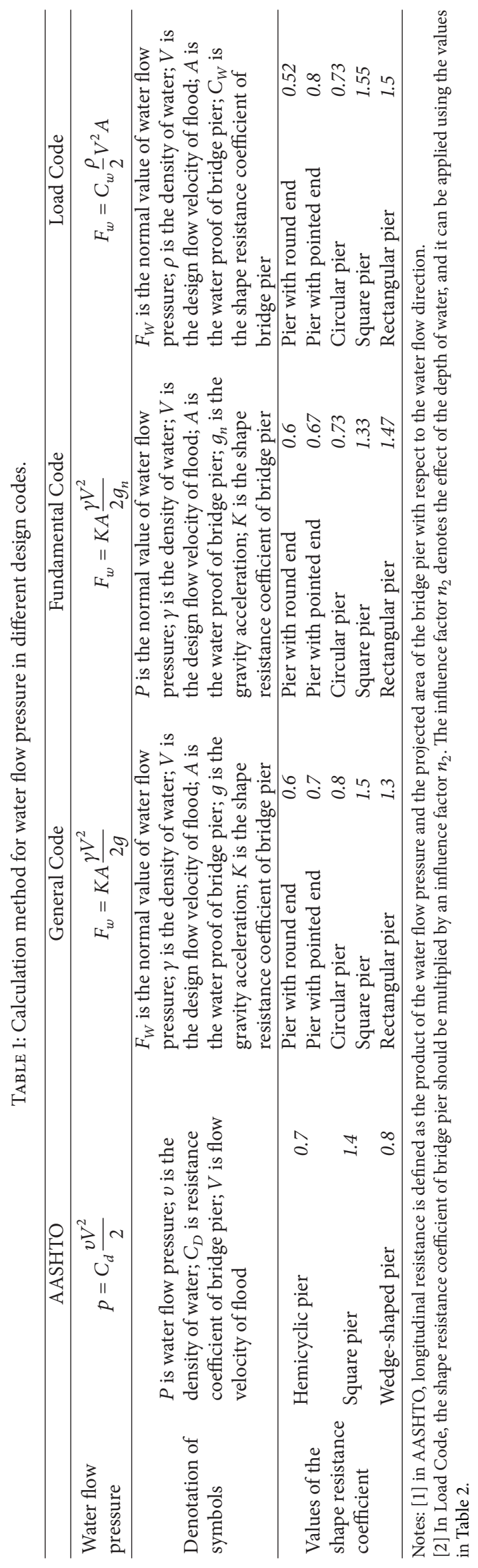


and when the S-ratio equals $h / H=1.0$, the F-Sc reaches a maximum value of 1.15 . When the $S$-ratio is not smaller than $1 / 2$, and the flood flowing velocity is larger than $4.0 \sim 6.0 \mathrm{~m} / \mathrm{s}$, the F-Sc decreases as the flood flowing velocity increases and finally trends towards a stable constant. Under this case, when the S-ratio equals $h / H=0.75$, the F-Sc reaches a maximum value of 1.1 and when S-ratio equals $h / H=1.0$, the $\mathrm{F}-\mathrm{Sc}$ reaches a maximum value of 1.06 . Based on these conclusions, it is found that the fluid-structure coupling effect has a low influence on the analytical results and, therefore, can be neglected when static analysis is performed on the bridge pier.

\section{Comparison of the Numerical Results with Those of Code Methods}

5.1. Calculation Methods for Determination of the Water Pressure in the Design Codes. Calculation methods for determination of the water flow pressure are specified in various codes at China and abroad. Table 1 lists the specific methods elaborated in AASHTO LRFD Bridge Design Specifications (AASHTO) [20], General Code for Design of Highway Bridges and Culverts (General Code) [21], Fundamental Code for Design on Railway Bridge and Culvert (Fundamental Code) [22], and Load Code for Harbor Engineering (Load Code) [23].

It can be seen from Table 2 that the calculation methods in various codes for determination of the water flow force are similar to each other. The formulas used in these codes are similar in formulation and the symbols in these formulas also have similar meanings, only with an exception that the values of the shape resistance coefficient of bridge pier vary with each other. Taking the circular column pier as an example, the value of the shape resistance coefficient of bridge pier is defined as 0.7 in AASHTO, and the values are $0.8,0.73$, and 0.73 , respectively in General Code, Fundamental Code, and Load Code. Although the values are the same in Fundamental Code and Load Code, it is stipulated in the Load Code that this value should be modified by an influence factor $n_{2}$, which accounts for the effect of the water depth. It is found that the value of the shape resistance coefficient of bridge pier is the largest in General Code under the same water flow velocity.

5.2. Comparison of the Numerical Results with Those of Code Methods. The analytical results considering the fluid-structure coupling effect are compared with the calculation results using the formulas provided by the aforementioned design codes, that is, AASHTO LRFD Bridge Design Specifications (AASHTO), General Code for Design of Highway Bridges and Culverts (General Code), Fundamental Code for Design on Railway Bridge and Culvert (Fundamental Code), and Load Code for Harbor Engineering (Load Code). The comparative results are shown in Figure 7.

From Figure 7, it can be seen that the water flow pressure provided by the General Code is the largest, and the results provided by the Fundamental Code and AASHTO are second and third largest, respectively, and the smallest result is derived by using the method stipulated in the Load Code. The analytical result considering the fluid-structure coupling
TABLE 2: The values of the influence factor $n_{2}$.

\begin{tabular}{ccccccccc}
\hline$H / D$ & 1 & 2 & 4 & 6 & 8 & 10 & 12 & $\geq 14$ \\
\hline$n_{2}$ & 0.76 & 0.78 & 0.82 & 0.85 & 0.89 & 0.93 & 0.97 & 1 \\
\hline
\end{tabular}

Notes: $H$ is the depth of water; $D$ is the width of the pier upstream face.

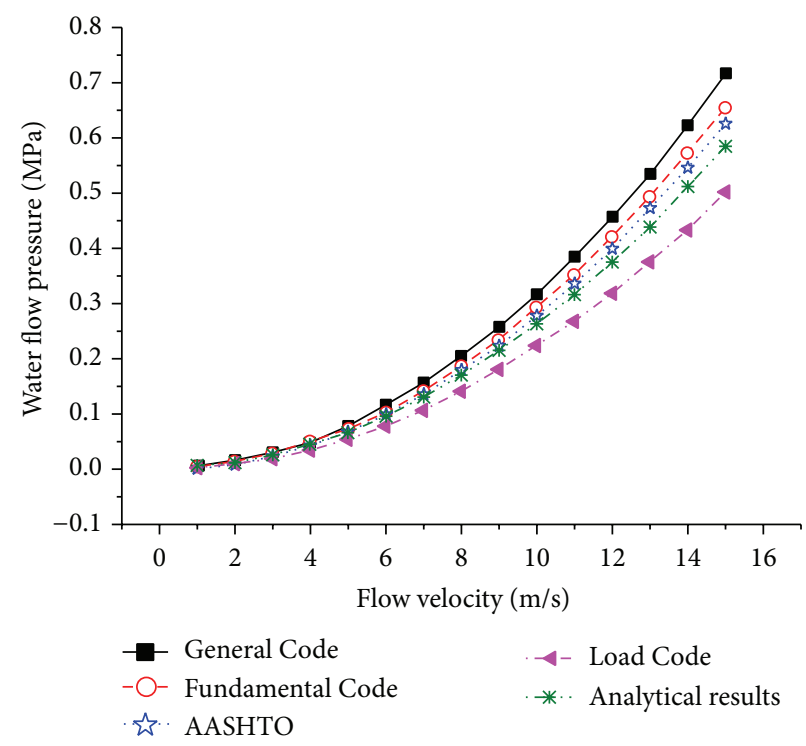

FIGURE 7: Variation curves of the water flow pressure with respect to the flow velocity when the S-ratio is $h / H=0.25$, using the formulas in the design codes and from analytical results considering bidirection fluid-structure coupling effect.

effect ranges between the results provided by AASHTO and Load Code. It seems that the calculation method provided by the General Code is conservative when it is applied in bridge design.

\section{Conclusions}

From the comparative analysis, the following conclusions can be derived for further research and practical reference.

(1) When the flood impacts the bridge pier in a transient state, the response of the bridge pier under the water pressure should be modified by an impact amplification coefficient, which varies with the flood flow velocity and the ratio of the pier depth submerged in the flood to the total pier height.

(2) The influence of fluid-structure coupling effect can be neglected, when static analysis is performed on the bridge pier around which the flood flows in a stable state.

(3) The water flow pressure using the method provided by the General Code for Design of Highway Bridges and Culverts is the largest, while the results provided by the Load Code for Harbor Engineering is the smallest. The analytical result considering the fluid-structure 
coupling effect ranges between the above two results. And it seems that the calculation method provided by the General Code for Design of Highway Bridges and Culverts is conservative.

\section{Conflict of Interests}

The authors declare that there is no conflict of interests regarding the publication of this paper.

\section{References}

[1] C. Storey and N. Delatte, "Lessons from the collapse of the Schoharie Creek Bridge," in Proceedings of the 3rd Forensic Engineering Congress, pp. 158-167, October 2003.

[2] M. X. Cao, Z. Liu, and J. Meng, "Statistical analysis and reflections on bridge deficiencies and disasters in the United States," Highway, vol. 7, no. 7, pp. 162-167, 2009.

[3] J. J. Sousa and L. Bastos, "Multi-temporal SAR interferometry reveals acceleration of bridge sinking before collapse," Natural Hazards and Earth System Sciences, vol. 13, no. 3, pp. 659-667, 2013.

[4] C. Y. Liaw and A. K. Chopra, "Dynamics of towers surrounded by water," Earthquake Engineering \& Structural Dynamics, vol. 3, no. 1, pp. 33-49, 1974.

[5] L. G. Olson and K.-J. Bathe, "Analysis of fluid-structure interactions. a direct symmetric coupled formulation based on the fluid velocity potential," Computers \& Structures, vol. 21, no. 1-2, pp. 21-32, 1985.

[6] Q.-X. Yan, H.-W. Liu, and Z. Wang, "Influence of boundary character of reservoir bottom on hydrodynamics in fluidstructure systems," Journal of Southwest Jiaotong University, vol. 37, no. 3, pp. 246-249, 2002.

[7] X. Z. Zhang, W. P. Huang, and H. J. Li, "Nonlinear dynamic analysis of offshore platform considering fluid-structure interaction," Periodical of Ocean University of China (Natural Science Edition), vol. 35, no. 5, pp. 823-826, 2005.

[8] J. F. Sigrist and S. Garreau, "Dynamic analysis of fluid-structure interaction problems with modal methods using pressurebased fluid finite elements," Finite Elements in Analysis and Design, vol. 43, no. 4, pp. 287-300, 2007.

[9] R. J. Qian, S. L. Dong, and X. F. Yuan, "Advances in research on fluid-structure interaction theory," Spatial Structures, vol. 14, no. 1, pp. 6-18, 2008.

[10] H. M. Xi, W. Zhang, and M. H. Yao, "Periodic and chaotic oscillations of the fluid conveying pipes with pulse fluid," Journal of Dynamics and Control, vol. 6, no. 3, pp. 243-248, 2008.

[11] G. X. Wang and W. Q. Sun, "Numerical analysis of dynamic charactersitcs of straight pipes with time-varying internal flow velocity," Coastal Engineering, vol. 29, no. 1, pp. 8-14, 2010.

[12] Y. C. Li and G. W. Li, "Wave current forces on the pile group of base foundation for the East Sea Bridge, China," Journal of Hydrodynamics, vol. 19, no. 6, pp. 661-670, 2007.

[13] J. X. Yang, F. Lei, and K. Li, "Analysis of vibration of underwater bridge pier structure," World Bridges, vol. 3, pp. 43-45, 2009.

[14] Y. C. Li, "Aspect of the normalization of hydrodynamic coefficients in Morison equation," Journal of Hydrodynamics, Series A, vol. 13, no. 3, pp. 329-337, 1998.
[15] V. Sundar, V. Vengatesan, G. Anandkumar, and A. Schlenkhoff, "Hydrodynamic coefficients for inclined cylinders," Ocean Engineering, vol. 25, no. 4-5, pp. 277-294, 1998.

[16] Ministry of Transport of the People's Republic of China, Code of Hydrology for Sea Harbor (JTS 145-2-2013), China Communications Press, Beijing, China, 2013.

[17] Y. Lan, H. Liu, F. X. Huang et al., "Experimental studies on hydrodynamic loads on piles and slab of Donghai bridge-part II: hydrodynamic forces on pile array and slab in wave current combinations," Journal of Hydrodynamics, Series A, vol. 20, no. 3, pp. 332-339, 2005.

[18] L.-P. Li and L. Cui, "Prediction of maximum scour depth around large-diameter cylinder under the effects of both wave and current," Journal of Hydrodynamics, vol. 17, no. 1, pp. 74-79, 2005.

[19] B. Miquel and N. Bouaanani, "Practical dynamic analysis of structures laterally vibrating in contact with water," Computers and Structures, vol. 89, no. 23-24, pp. 2195-2210, 2011.

[20] AASHTO, AASHTO LRFD Bridge Design Specifications, AASHTO, Washington, DC, USA, 2004.

[21] Ministry of Transport of the People's Republic of China, General Code for Design of Highway Bridges and Culverts (JTG D602004), China Communications Press, Beijing, China, 2004.

[22] Ministry of Transport of the People's Republic of China, Fundamental Code for Design on Railway Bridge and Culvert (TB 10002.1-2005), China Railway Publishing House, Beijing, China, 2005.

[23] Ministry of Transport of the People's Republic of China, Load Code for Harbor Engineering (JTS 144-1-2010), China Communications Press, Beijing, China, 2010. 


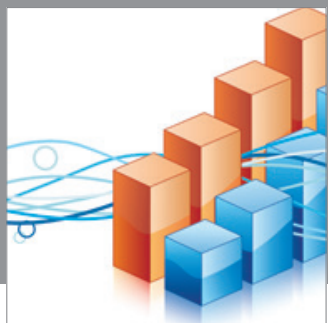

Advances in

Operations Research

mansans

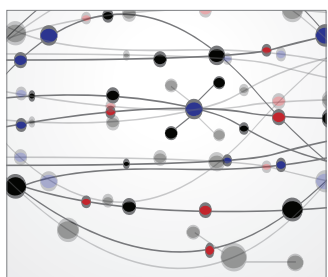

The Scientific World Journal
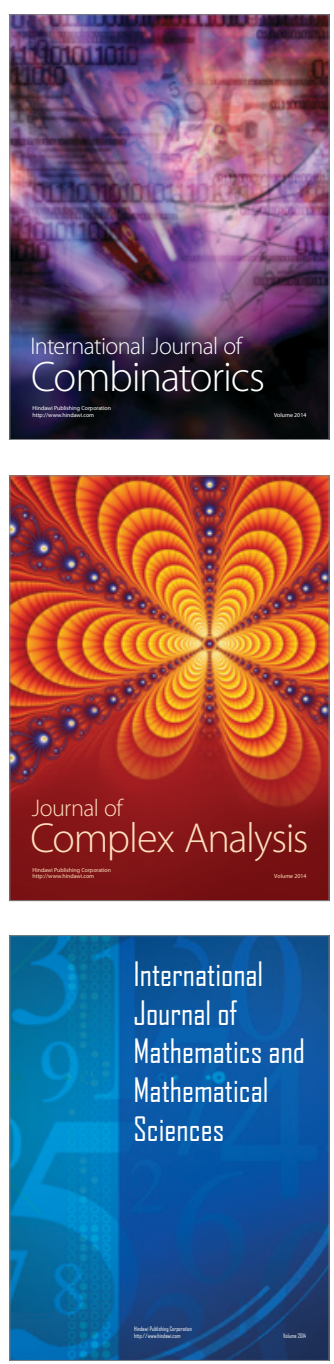
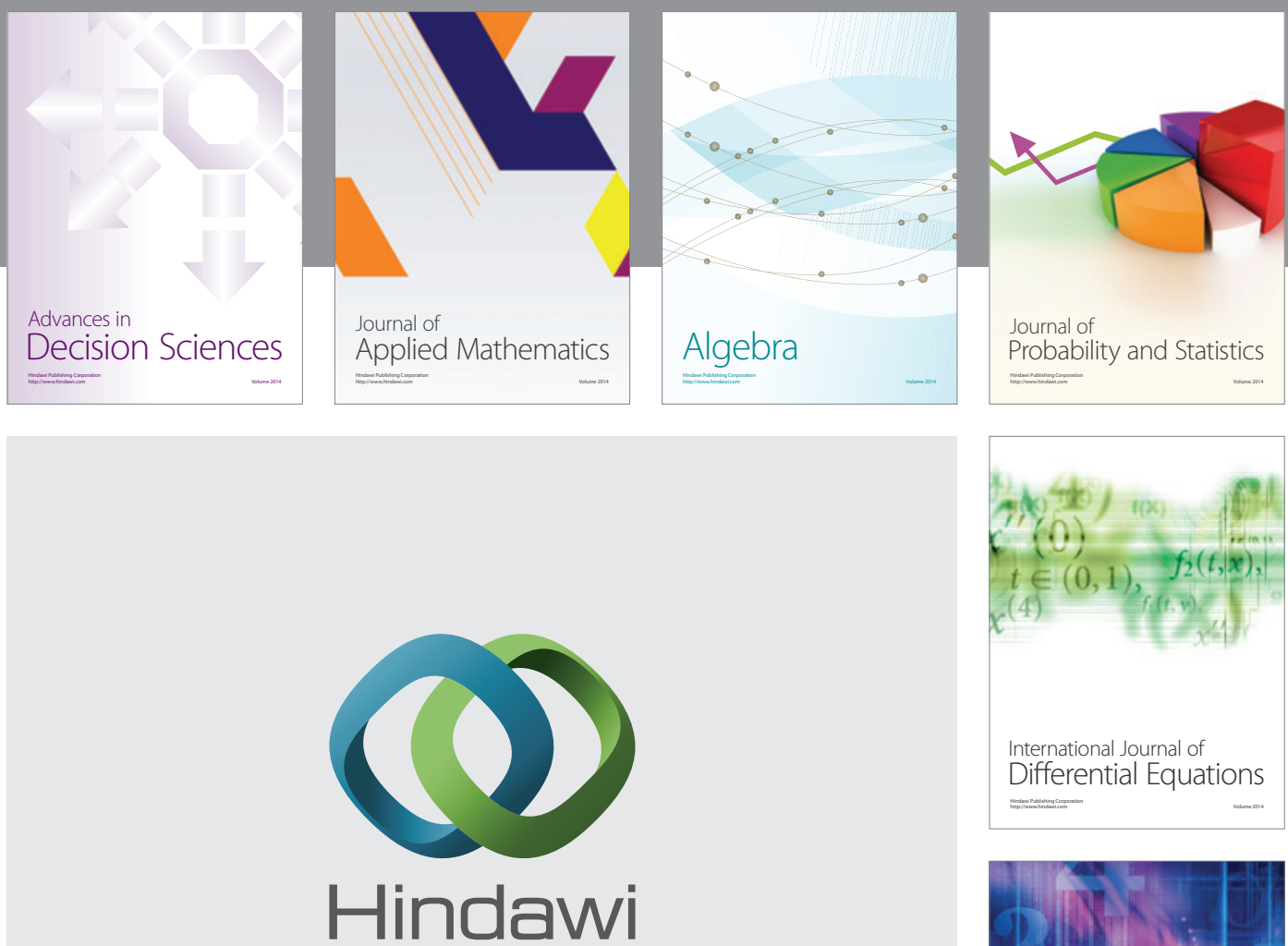

Submit your manuscripts at http://www.hindawi.com
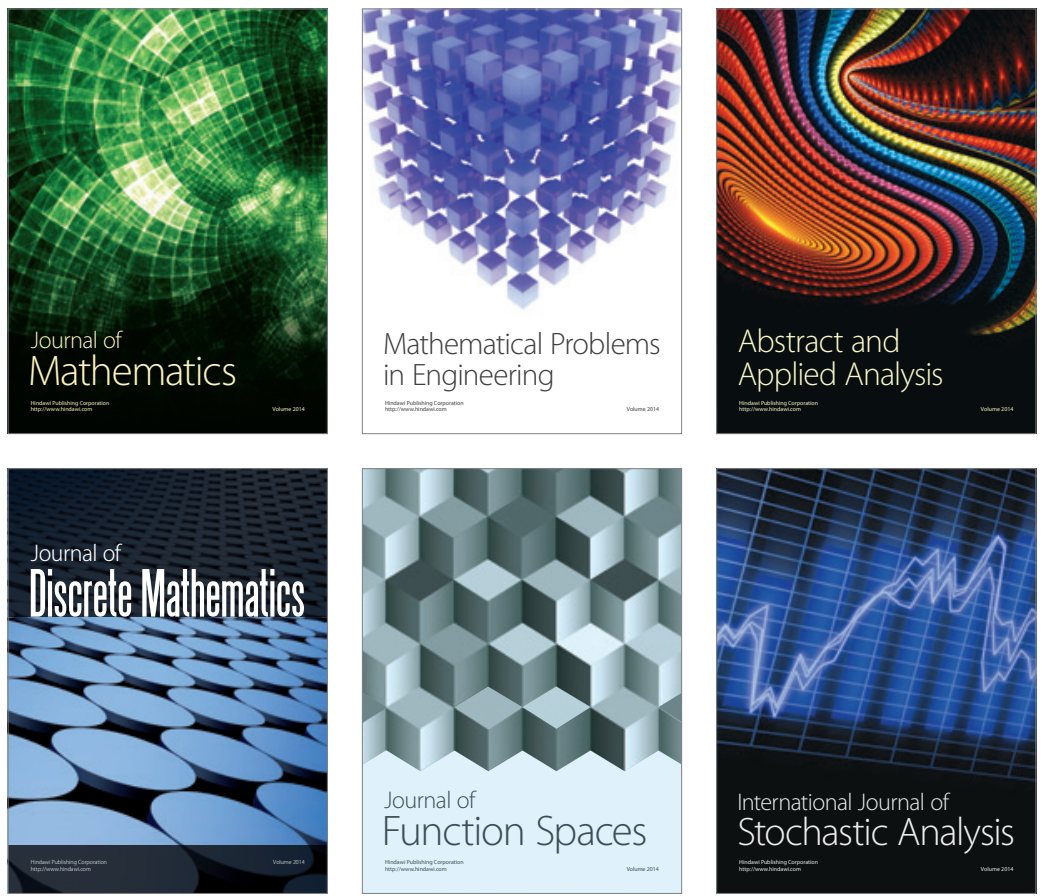

Journal of

Function Spaces

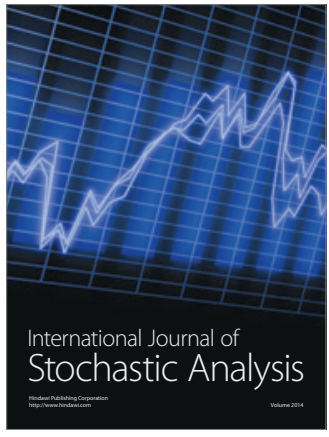

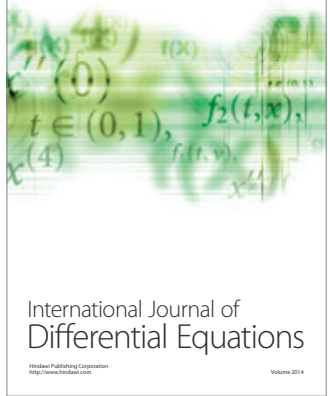
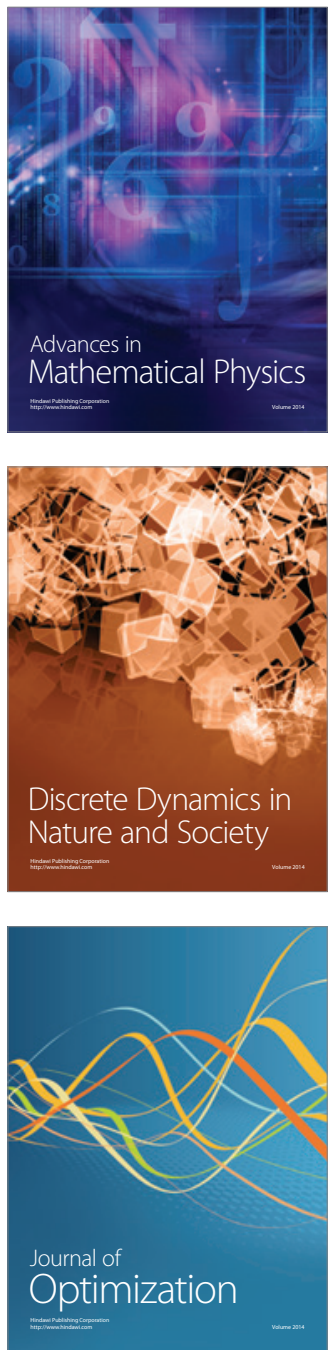